\title{
Sarcopenia as a predictor of mortality among the critically ill in an intensive care unit: a systematic review and meta-analysis
}

\author{
Xiao-Ming Zhang ${ }^{1 \dagger}$, Denghong Chen ${ }^{2 \dagger}$, Xiao-Hua Xie $^{3^{*}}$, Jun-E Zhang ${ }^{4^{*}}$, Yingchun Zeng ${ }^{5}$ and Andy SK Cheng ${ }^{6}$
}

\begin{abstract}
Background: The evidence of sarcopenia based on CT-scan as an important prognostic factor for critically ill patients has not seen consistent results. To determine the impact of sarcopenia on mortality in critically ill patients, we performed a systematic review and meta-analysis to quantify the association between sarcopenia and mortality.

Methods: We searched studies from the literature of PubMed, EMBASE, and Cochrane Library from database inception to June 15, 2020. All observational studies exploring the relationship between sarcopenia based on CTscan and mortality in critically ill patients were included. The search and data analysis were independently conducted by two investigators. A meta-analysis was performed using STATA Version 14.0 software using a fixedeffects model.

Results: Fourteen studies with a total of 3,249 participants were included in our meta-analysis. The pooled prevalence of sarcopenia among critically ill patients was $41 \%$ (95\% Cl:33-49\%). Critically ill patients with sarcopenia in the intensive care unit have an increased risk of mortality compared to critically ill patients without sarcopenia ( $\left.\mathrm{OR}=2.28,95 \% \mathrm{Cl}: 1.83-2.83 ; \mathrm{P}<0.001 ; \mathrm{I}^{2}=22.1 \%\right)$. In addition, a subgroup analysis found that sarcopenia was associated with high risk of mortality when defining sarcopenia by total psoas muscle area (TPA, OR $=3.12,95 \% \mathrm{Cl}: 1.71-5.70$ ), skeletal muscle index (SMI, OR = 2.16,95\%Cl:1.60-2.90), skeletal muscle area (SMA, OR = $2.29,95 \% \mathrm{Cl}: 1.37-3.83)$, and masseter muscle(OR $=2.08,95 \% \mathrm{Cl}: 1.15-3.77)$. Furthermore, critically ill patients with sarcopenia have an increased risk of mortality regardless of mortality types such as in-hospital mortality (OR $=1.99$, $95 \% \mathrm{Cl}: 1.45-2.73)$, 30-day mortality( $\mathrm{OR}=2.08,95 \% \mathrm{Cl}: 1.36-3.19)$, and 1-year mortality (OR=3.23, $95 \% \mathrm{Cl}: 2.08-5.00)$.

Conclusions: Sarcopenia increases the risk of mortality in critical illness. Identifying the risk factors of sarcopenia should be routine in clinical assessments and offering corresponding interventions may help medical staff achieve good patient outcomes in ICU departments.
\end{abstract}

Keywords: Sarcopenia, Mortality, Critically ill, Intensive care unit, Meta-analysis

\footnotetext{
*Correspondence: 13560779836@163.com; zhangje@mail.sysu.edu.cn

${ }^{+}$Xiao-Ming Zhang and Denghong Chen are co-first author.

${ }^{3}$ Department of Nursing, The Second People's Hospital of Shenzhen, The

First Affiliated Hospital of Shenzhen University, Shenzhen, China

${ }^{4}$ School of Nursing, Sun Yat-sen University, Guangzhou, China

Full list of author information is available at the end of the article
}

(C) The Author(s). 2021 Open Access This article is licensed under a Creative Commons Attribution 4.0 International License, which permits use, sharing, adaptation, distribution and reproduction in any medium or format, as long as you give appropriate credit to the original author(s) and the source, provide a link to the Creative Commons licence, and indicate if changes were made. The images or other third party material in this article are included in the article's Creative Commons licence, unless indicated otherwise in a credit line to the material. If material is not included in the article's Creative Commons licence and your intended use is not permitted by statutory regulation or exceeds the permitted use, you will need to obtain permission directly from the copyright holder. To view a copy of this licence, visit http://creativecommons.org/licenses/by/4.0/. The Creative Commons Public Domain Dedication waiver (http://creativecommons.org/publicdomain/zero/1.0/) applies to the data made available in this article, unless otherwise stated in a credit line to the data. 


\section{Background}

Critically ill patients in intensive care units often suffered from multiple organ dysfunction, which increased the risk of mortality. Mortality rates - especially among oncology and hematology patients - have steadily decreased over time, thanks to dramatic progress in medical care [1]. However, the mortality of critically ill patients is still one of the most important issues, especially for the elderly patients with comorbidities and functional decline. There are several reasons that account for critically ill patients' mortality, such as malnutrition [2], sepsis [3], immobility, and multiple organ dysfunction syndrome [4]. Therefore, it is important to predict mortality and stratify the risk of death. For decades, numerous scoring systems have been developed to predict clinical outcomes in critical illness, such as Sequential Organ Failure Assessment (SOFA) [5], systemic inflammatory response syndrome [6], and Acute Physiology and Chronic Health Evaluation APACHE-II [7]. However, these scoring systems have shown relatively poor predictable performance. Therefore, further studies are required to investigate more precise parameters in order to better predict poor clinical outcomes.

Sarcopenia is characterised by declining loss of muscle mass, strength, and physical function [8]. There is an increasing number of studies that show critically ill patients usually suffer from sarcopenia, due to factors such as nutritional status, inflammation, coexistence of disease, and inactivity [9]. It is estimated that the prevalence of sarcopenia is approximately $30-70 \%$ in intensive care units $[10,11]$. Sarcopenia has been confirmed to have an association with adverse clinical outcomes, such as falls, fractures, poor quality of life, mortality, and cognitive dysfunction among older adults in the community, nursing homes, or ICU [12-15]. Recently, Xia and colleagues published a metaanalysis concluding that injured patients with sarcopenia are at increased risk of mortality, with a two-fold increased risk compared to patient groups without sarcopenia [16]. Only four studies were conducted in ICU departments. Additionally, a number of recent studies have explored the relationship between sarcopenia and mortality in critically ill patients in the ICU. Some have shown that sarcopenia significantly increases mortality risk [10, 17-21], while others found no such an association [11, 22-25]. Given the inconsistent results, it is necessary to synthesize the evidence to explore the role sarcopenia may play in mortality in critically ill patients in the ICU. Therefore, we conducted a systematic review and meta-analysis to confirm whether critically ill patients with sarcopenia are at increased risk of mortality in ICU departments, which could inform prognostication on critically ill patients.

\section{Methods}

This study was conducted and reported according to the Preferred Reporting Items for Systematic Reviews
(PRISMA) guidelines [26], with a detailed checklist shown in supplementary Table 1 . We have registered our protocol in PROSPERO with the number of CRD42020211548. The GRADE (Grading of Recommendations, Assessment, Development and Evaluation) approach was used to categorize the level of evidence.

\section{Search strategy}

Two authors (XMZ, DHC) independently searched the electronic database, including PubMed, Embase, and Cochrane CENTRAL Library, from database inception until June 15, 2020. The search strategy includes keywords and medical subject headings (Mesh), including sarcopenia, critically ill (critical illness), or intensive care. The detailed search methods are shown in Supplemental File 1 . We conducted a manual search of additional references from the selected articles. In addition, we searched the grey studies from Google and contacted with the authors of the unpublished study. The search results were discussed and confirmed by our team.

\section{Study selection}

All of the articles identified from the electronic database were independently evaluated by two authors (YCZ and DHC). To start with, title and abstract were screened to confirm whether an article was potentially relevant. After that, the two authors checked the full text to identify whether it met the priority eligibility criteria. Any disagreements were addressed through team discussion and consensus.

\section{Inclusion and exclusion criteria}

We established a priori inclusion criteria as follows: (i)The study design included observational studies; (ii) We included participants 18 years of age and over from ICU departments; (iii) The study includes a clear definition of sarcopenia using a consensual method or the prevalence of sarcopenia; and (iv) The study has shown the relationship between sarcopenia and mortality (30day mortality, in-hospital mortality, 1-year mortality).

The exclusion criteria are as follows: (i) Article type: Conference, review articles, letters and laboratory research, case report; (ii) Using the sarcopenia index calculated as [(serum creatinine/serum cystatin C)x100] to report the association between SI (sarcopenia and index) and mortality; (iii) LMM (low muscle mass) was used as a continuous variable to report the association, but did not provide the results of association, between sarcopenia and mortality; (iv) Duplicate publication of articles; and (v) Languages other than English.

\section{Data extraction}

The two authors (ASKC and XHX) independently used Microsoft ${ }^{\circ}$ Excel 2016 to collect all data. The variables of 
the studies that were included were extracted as follows: Country, year of publication, time of CT scan, male/female ratio, age, prevalence of sarcopenia, sample size, definition of sarcopenia, cause of admission, study design and outcome. If the study reported more than two terms of mortality, such as 30-day mortality, 1-year mortality, the latter term was included. If mortality was shown in a multivariate analysis, we adopted the adjusted model, otherwise we calculated it. All data were checked by the two authors to achieve the final results.

\section{Quality assessment and risk of bias}

Study quality assessment was evaluated by both authors using the Newcastle-Ottawa Scale (NOS). It included six aspects, with the scale's total score, nine points [27]. The following NOS information included (i) Representativeness of the exposed cohort, (ii) comparability of the group, (iii) blinding of the investigators who measured the outcomes, (iv) time and completeness of follow-up, (v) contamination bias, and (vi) other potential sources of bias.

\section{Statistical analysis}

Both authors (XMZ and ASKC) independently used STATA Version 14.0 software to calculate pooled data and heterogeneity. The studies that were included reported Odds ratio (OR), and $95 \%$ confidence intervals (95\% CI) were extracted for future meta-analysis. We converted the effect of OR to $\ln (\mathrm{OR})$ for ratios in a meta-analysis, and subgroup analyses were conducted on different types of participants and outcomes. We performed Cochran's $Q$ test to examine statistical heterogeneity by using chi-square and $\mathrm{I}^{2}$ statistics. The $\mathrm{I}^{2}$ statistic describes the percentage of variation across studies due to heterogeneity. Low, moderate, and high heterogeneity are defined by $25 \%, 50 \%$, and $75 \%$ cut-off ( $\mathrm{I}^{2}$ values) respectively. If the $\mathrm{I}^{2}>50 \%$ or $p<0.10$, we defined these studies as having significant heterogeneity and used the random-effects model. Otherwise, the fixed-effects model was used. Furthermore, Begg's and Egger's tests were used to identify whether any publication bias existed, and sensitivity analysis was conducted to assess the stability of the results. We also used trial sequential analysis (TSA) to assess whether the results were robust and reliable [28].

\section{Assessment of evidence quality}

We displayed the evidence for each outcome using the methods recommended by GRADE. We rated the overall quality of evidence according to four categories: "high", "moderate", "low or very low". These criteria were based on the evaluation of identified risks of bias, indirectness, imprecision, inconsistency, and publication bias.

\section{Results}

\section{Study selection}

Our team initially searched 594 articles from three Internet databases. After removing the duplicates, 497 articles remained. YCZ and DHC then screened the titles and abstracts, deleting 469 irrelevant studies. A further 28 articles were screened for full-text assessment: six studies were reviews or case studies and four studies were conference papers. In addition, four studies were excluded for not reporting the association between sarcopenia and mortality, as they only provided the association between skeletal muscle index (SMI) as a continuous variable and mortality [29-32]. Therefore, 14 publications were finalised for analysis. (Shown in Figure S1).

\section{Study summary}

There were 14 studies with a total of 3,249 patients included in our meta-analysis. All of the studies that were included were retrospective cohort studies, with the exception of one [33], which was a prospective cohort study. A total of five studies was conducted in the US [10, 22, 25, 33, 34]; while China [21, 35], Japan [17, 24], and the Netherlands $[11,18]$ each had two studies, and Korea [20], Australia [23], and Brazil [19] each had one study respectively. All studies used CT. to detect sarcopenia. There were several outcomes reported in our meta-analysis. Seven studies used in-hospital mortality $[10,11,17,18,21,22,25]$, four studies used 30-day mortality $[19,23,24,35]$, and three studies used 1-year mortality $[20,33,34]$. The proportion of males among the studies that were included ranged from 51.40 to $69 \%$ (Table 1). Table S2 showed the result of each study with adjusted covariates. The pooled prevalence of sarcopenia among critically ill patients was $41 \%$ (95\% CI: $33-49 \%$; $p=0.000 ; \mathrm{I}^{2}=95.6 \%$ ) (Fig. 1).

\section{Study quality}

None of the studies was a randomized controlled study, and study quality was relatively moderate, ranging from 5 to 8 points NOS (Table S3).

\section{Mortality}

All studies that were included used mortality as the primary outcome. Our study showed that critically ill patients with sarcopenia have an increased risk of mortality when compared to those without sarcopenia $\left(\mathrm{OR}=2.28,95 \% \mathrm{CI}: 1.83-2.83, \mathrm{I}^{2}=22.1 \%\right)$ (Fig. 2). In addition, pooled data showed a significantly high risk of in-hospital mortality in critically ill patients with sarcopenia, compared to non-sarcopenic patients $(\mathrm{OR}=1.99$, $\left.95 \% \mathrm{CI}: 1.45-2.73, \mathrm{I}^{2}=21.9 \%\right)$, 30-day mortality (OR = 2.08, $95 \% \mathrm{CI}: 1.36-3.19, \mathrm{I}^{2}=0.0 \%$ ), and 1-year mortality $\left(\mathrm{OR}=3.23, \quad 95 \% \mathrm{CI}: 2.08-5.00, \mathrm{I}^{2}=56.4 \%\right) \quad$ (shown in Fig. 3). Meanwhile, we examined the minimum sample 


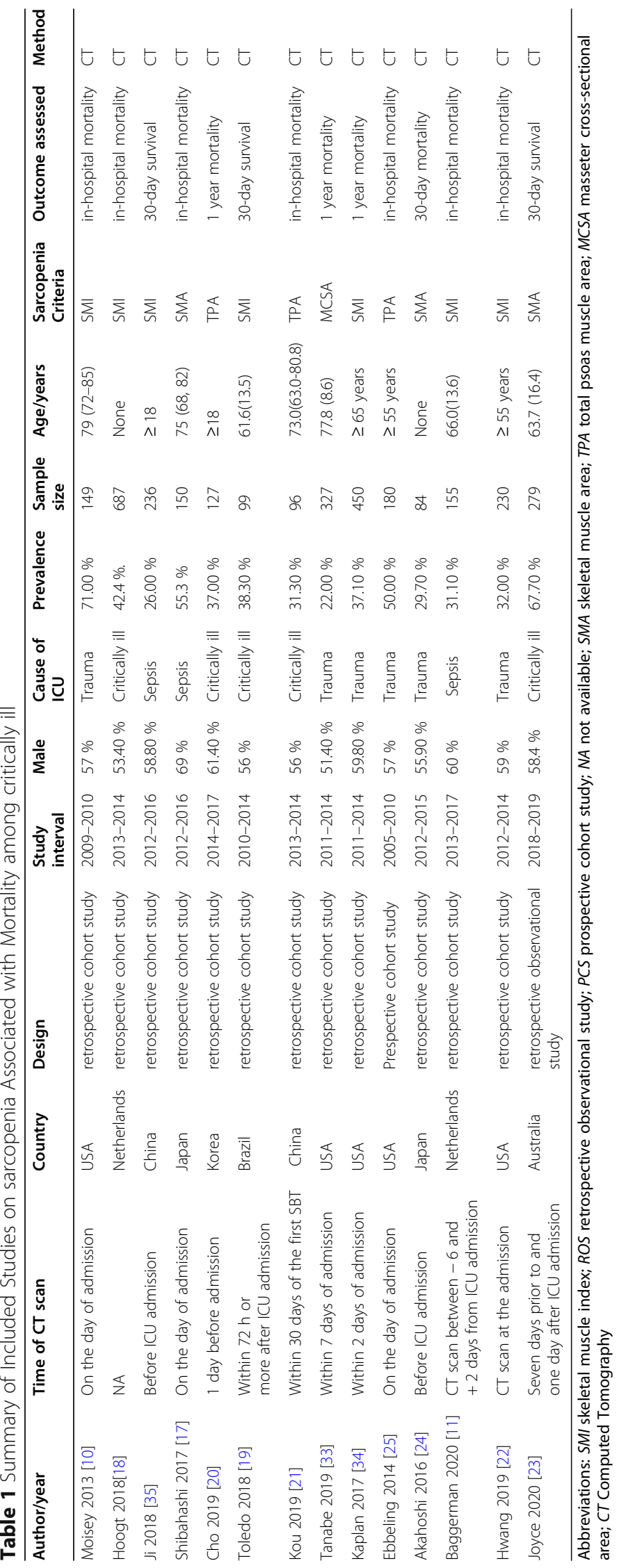




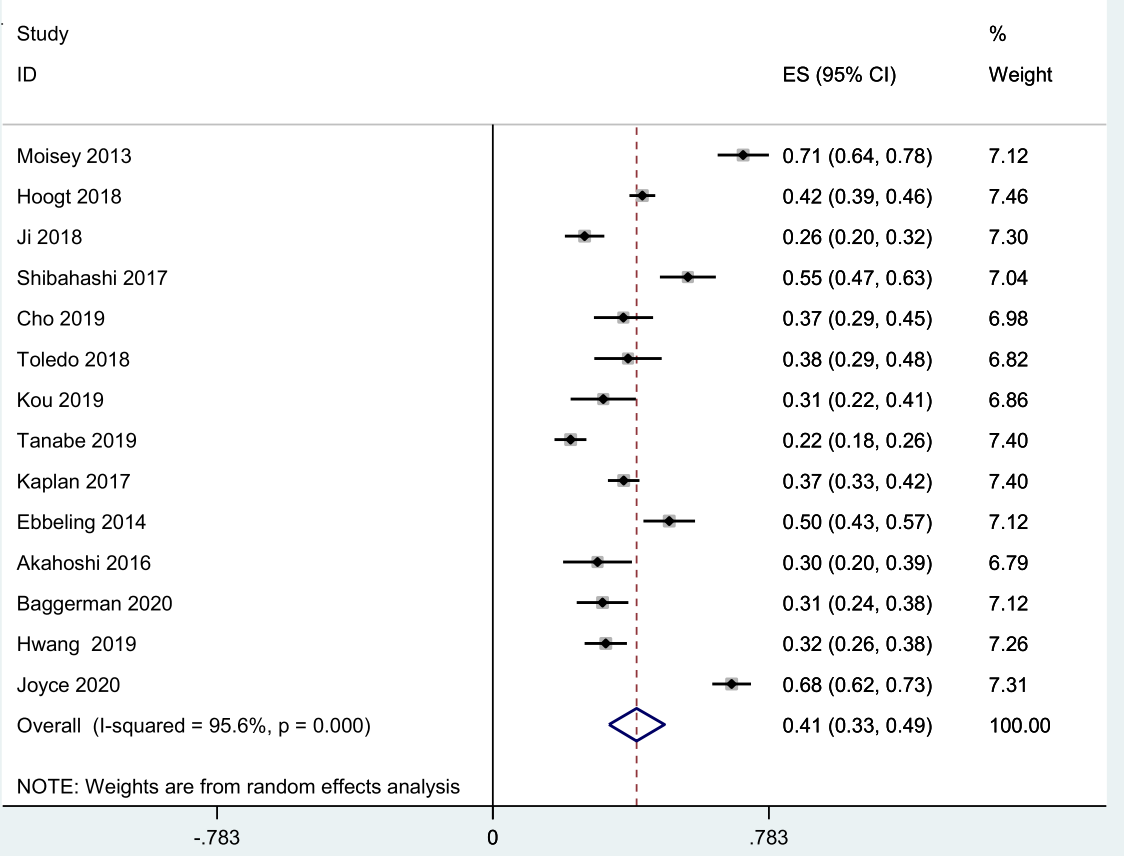

Fig. 1 Pooled prevalence of sarcopenia in critically ill patients

\begin{tabular}{|c|c|c|c|}
\hline \multicolumn{2}{|l|}{ Study } & & $\%$ \\
\hline ID & & $\mathrm{OR}(95 \% \mathrm{Cl})$ & Weight \\
\hline Moisey 2013 & & $2.30(1.04,5.08)$ & 7.64 \\
\hline Hoogt 2018 & - & $2.36(1.14,4.89)$ & 9.03 \\
\hline Ji 2018 & & $2.30(1.10,3.70)$ & 13.06 \\
\hline Shibahashi 2017 & 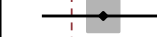 & $3.27(1.61,6.63)$ & 9.59 \\
\hline Cho 2019 & 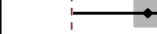 & $5.47(2.31,12.98)$ & 6.45 \\
\hline Toledo 2018 & & $2.74(1.02,7.35)$ & 4.93 \\
\hline Kou 2019 & o- & $5.07(1.06,24.28)$ & 1.96 \\
\hline Tanabe 2019 & - & $2.08(1.15,3.77)$ & 13.63 \\
\hline Kaplan 2017 & $\rightarrow$ & $5.36(2.03,14.16)$ & 5.09 \\
\hline Ebbeling 2014 & - & $1.20(0.44,3.26)$ & 4.79 \\
\hline Akahoshi 2016 & & $1.18(0.11,12.43)$ & 0.86 \\
\hline Baggerman 2020 & & $1.60(0.73,3.33)$ & 8.41 \\
\hline Hwang 2019 & & $0.98(0.43,2.27)$ & 6.94 \\
\hline Joyce 2020 & 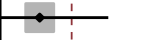 & $1.57(0.71,3.47)$ & 7.63 \\
\hline Overall (I-squared $=22.1 \%, p=0.214$ ) & $\lambda$ & $2.28(1.83,2.83)$ & 100.00 \\
\hline
\end{tabular}

Fig. 2 Meta-analysis of the association between sarcopenia and mortality in critically ill patients 


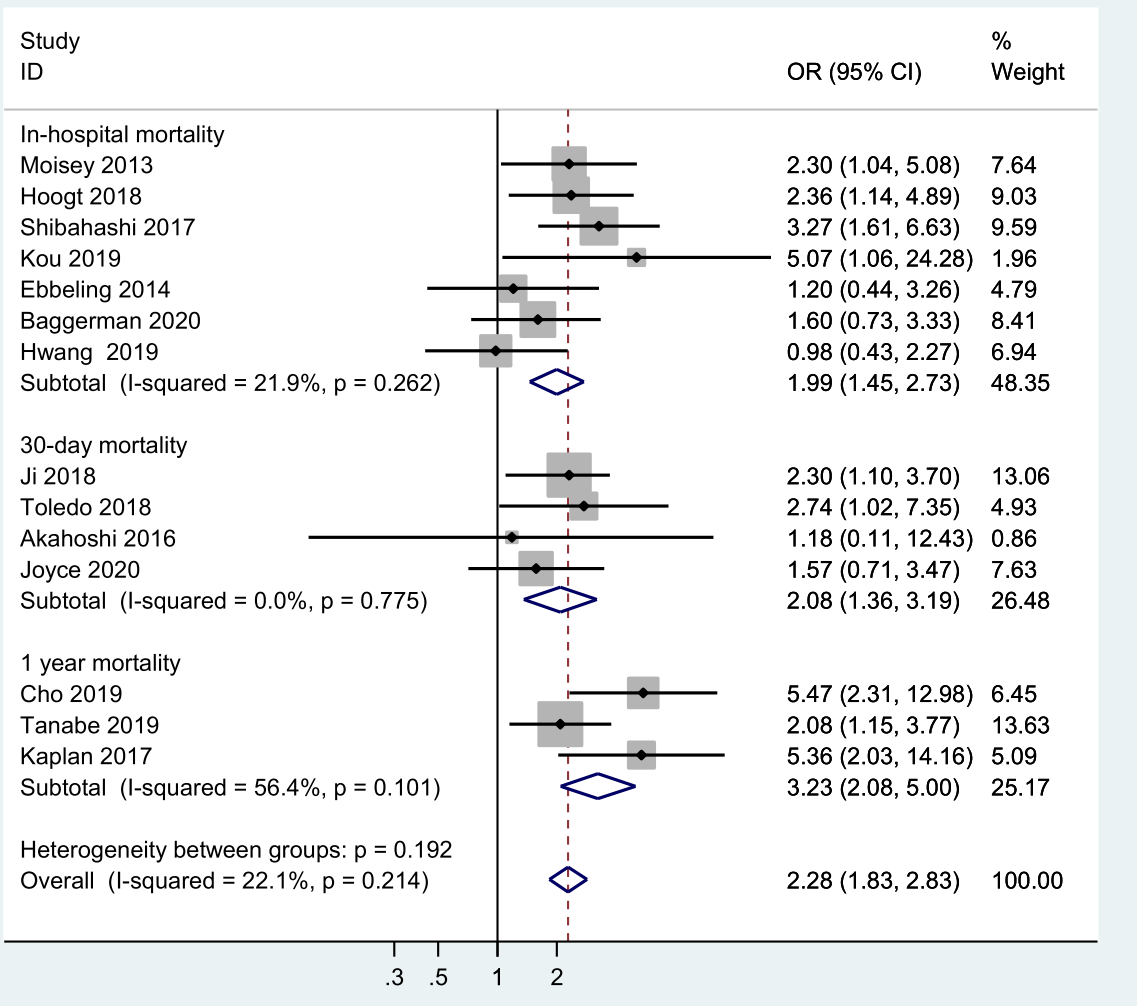

Fig. 3 Subgroup meta-analysis of the association between sarcopenia and mortality in critically ill patients by outcome type

size required by trial sequential analysis for metaanalysis and found that 1,105 participants were required. There were 3,249 participants included from these 14 studies. In addition, as we can see the $\mathrm{Z}$ line has crossed both information size and conventional boundaries, indicating that the association between sarcopenia and allcause mortality in our analysis was reliable and robust. (Figure S2).

\section{Subgroup analyses \\ Reasons for ICU admission}

Six studies clearly reported that the reason for admission to ICU was trauma [10, 22, 24, 25, 33, 34], while three studies indicated sepsis as the reason for admission [11, 17, 35]. The patients in the other studies showed complex reasons for ICU department admittance [18-21, 23]. Therefore, we performed a subgroup analysis of the reasons for admission, and found that patients with sarcopenia had an increased mortality risk when compared to patients without sarcopenia among sepsis patients $\left(\mathrm{OR}=2.32,95 \%\right.$ CI:1.57-3.44; $\left.\mathrm{I}^{2}=0.0 \%\right)$. The results were similar among trauma patients $(\mathrm{OR}=1.94,95 \% \mathrm{CI}$ : $\left.1.36-2.75, \mathrm{I}^{2}=38.1 \%\right)$ and patients admitted for other mixed reasons $\left(\mathrm{OR}=2.75,95 \% \mathrm{CI}: 1.84-4.10, \mathrm{I}^{2}=21.7 \%\right)$ (Fig. 4).

\section{Different definitions of sarcopenia}

There are several methods to measure skeletal muscle mass, including total skeletal muscle area or psoas muscle area, as well as masseter cross-sectional area. Detailed information, including muscle measurement and cut-off values, are shown in Table 2 . Therefore, we performed a subgroup analysis based on different measures to detect whether there was a difference. Our results showed that critically ill patients with sarcopenia had an increased risk of mortality, compared with non-sarcopenic patients, when using SMI to define sarcopenia $(\mathrm{OR}=2.16$, $\left.95 \% \mathrm{CI}: 1.60-2.90, \mathrm{I}^{2}=22.9 \%\right)$. In addition, we found similar results when using TPA $(\mathrm{OR}=3.12$, $95 \% \mathrm{CI}$ : $1.71-$ $\left.5.70, \mathrm{I}^{2}=63.6 \%\right)$ or SMA (OR $=2.29,95 \% \mathrm{CI}: 1.37-3.83$, $\left.\mathrm{I}^{2}=6.8 \%\right)$ to define sarcopenia. The association between sarcopenia and mortality, based on masseter crosssectional area, was also significantly different $(\mathrm{OR}=2.08$, 95 \%CI:1.15-3.77) (Fig. 5).

\section{Subgroup analyses according to region}

Five studies were conducted in Asian populations [17, $20,21,24,35]$, and nine studies in Western populations $[10,11,18,19,22,23,25,33,34]$. Therefore, we performed a subgroup analysis based on geographical region. The results showed that critically ill Asian patients 


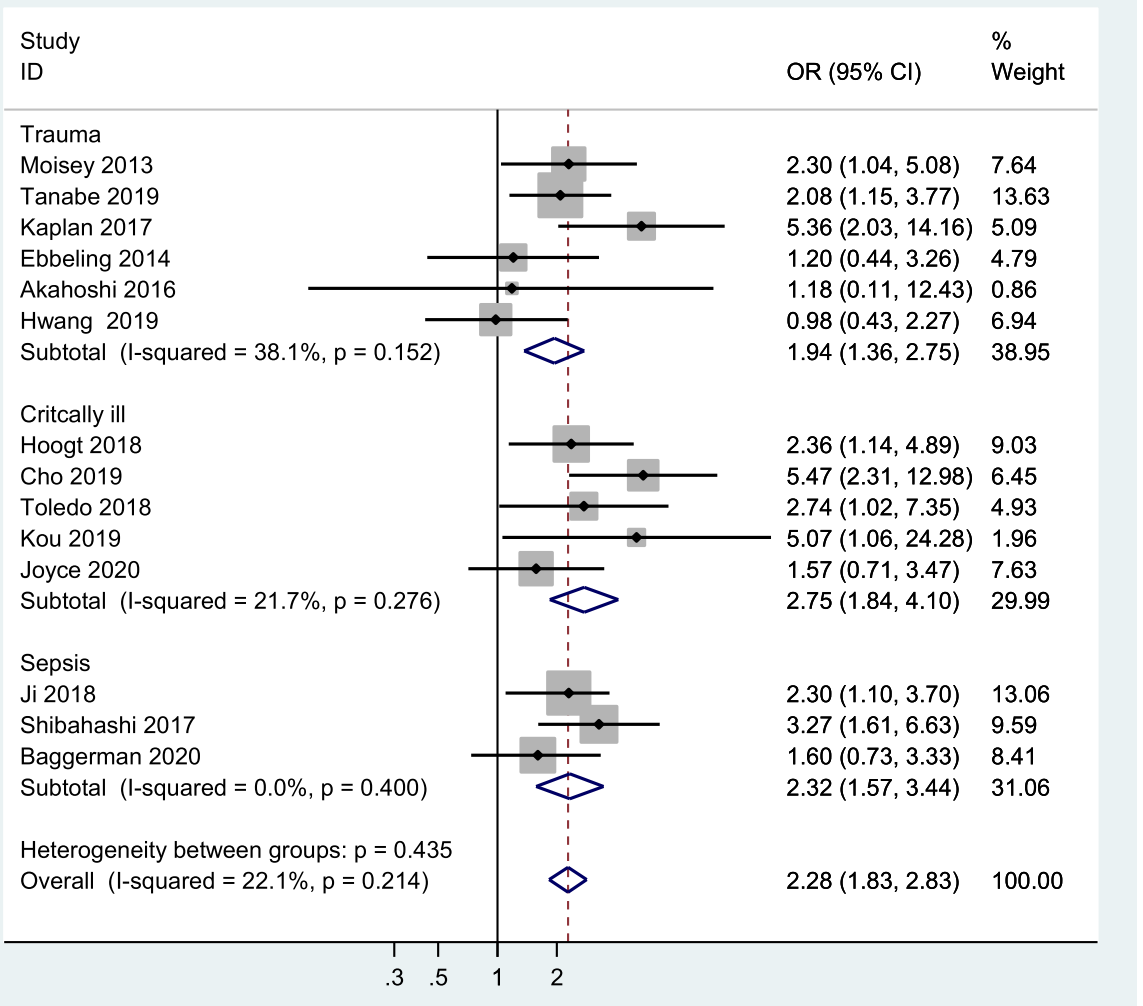

Fig. 4 Subgroup meta-analysis of the association between sarcopenia and mortality in critically ill patients by cause of disease

with sarcopenia have an increased risk of mortality, compared to critically ill Asian patients without sarcopenia $\quad\left(\mathrm{OR}=3.14, \quad 95 \% \quad \mathrm{CI}: 2.13-4.63 ; \quad \mathrm{I}^{2}=0.0 \%\right)$. Similar results were found in Western populations $\left(\mathrm{OR}=1.96, \quad 95 \%\right.$ CI:1.50-2.55; $\left.\mathrm{I}^{2}=12.8 \%\right)$. Figure 6 summarises the results.

\section{Subgroup analysis by age}

As age is an important confounding factor, we performed a subgroup analysis based on two age groups (more than or equal to 70 years versus less than 70 years). The results showed that the association between mortality and sarcopenia was observed in both of these age groups $\left(\mathrm{OR}=2.33\right.$, $95 \% \mathrm{CI}: 1.63-3.33 ; \mathrm{I}^{2}=0.0 \%$ versus $\mathrm{OR}=2.25,95 \% \mathrm{CI}: 1.70-2.96 ; \mathrm{I}^{2}=38.5 \%$, respectively). See Figure S3.

\section{Publication bias and sensitivity analysis}

The results of Begg's and Egger's tests show no significant bias ( $P=0.956, P=0.785$, respectively) (Figure S4). In addition, sensitivity analysis results show that the pooled result did not result in significant change after one study was omitted each time (Figure S5).

\section{Overall evidence quality}

Our study indicates the quality of evidence was low due to the risk of bias, indirectness, and imprecision (Table S4).

\section{Discussion}

Our study found that critically ill patients with sarcopenia have a 2.28 -fold(95 \% CI:1.83-2.83) increased risk of mortality compared to patients without sarcopenia, regardless of short- or long-term mortality. To the best of our knowledge, this is the first significant comprehensive study to systematically summarise evidence on the association between sarcopenia and mortality in intensive care units. Our study suggests that intensive care physicians should focus more on screening for sarcopenia and should recommend early and effective preventive programmes, such as resistance training or nutrition treatments, with the goal of reducing patient mortality rates in ICU departments.

The pooled prevalence of sarcopenia was $41 \%$ (95 \%CI: 33- 49\%), which is higher than among community-dwelling older adults [36]. In fact, the prevalence of sarcopenia varied among different participants and was also determined by measurements detecting muscle mass with different cut-off points. A recent study 
Table 2 Computed Tomography Assessment of sarcopenia

\begin{tabular}{|c|c|c|c|}
\hline Study & Muscles Measured & Level & Cut-off value/Definition \\
\hline Moisey 2013 & Skeletal Muscle Index & L3 & $\begin{array}{l}\text { Males }<55.4 \mathrm{~cm}^{2} / \mathrm{m}^{2} \\
\text { Females }<38.9 \mathrm{~cm}^{2} / \mathrm{m}^{2}\end{array}$ \\
\hline Hoogt 2018 & Skeletal muscle area index & L3 & No definition of sarcopenia \\
\hline Ji 2018 & Skeletal muscle area index & L3 & $\begin{array}{l}\text { Male }<40.8 \mathrm{~cm}^{2} / \mathrm{m}^{2} \\
\text { Female }<34.9 \mathrm{~cm}^{2} / \mathrm{m}^{2}\end{array}$ \\
\hline Shibahashi 2017 & Skeletal muscle area & L3 & $\begin{array}{l}\text { Men }<45.2 \mathrm{~cm}^{2} \\
\text { Women }<39.0 \mathrm{~cm}^{2}\end{array}$ \\
\hline Cho 2019 & psoas cross-sectional area & L3 & $\begin{array}{l}\text { Males }<5.45 \mathrm{~cm}^{2} / \mathrm{m}^{2} \\
\text { Female }<3.85 \mathrm{~cm}^{2} / \mathrm{m}^{2}\end{array}$ \\
\hline Toledo 2018 & Skeletal muscle area index & L3 & $\begin{array}{l}\text { Male }<55.27 \mathrm{~cm} 2 / \mathrm{m} 2 \\
\text { Female }<40.13 \mathrm{~cm} 2 / \mathrm{m} 2\end{array}$ \\
\hline Kou 2019 & Total psoas area & L3 & Male $<545 \mathrm{~mm}^{2} / \mathrm{m}^{2}$ Female $<385 \mathrm{~mm}^{2} / \mathrm{m}^{2}$ \\
\hline Tanabe 2019 & Masseter cross-sectional area & $\begin{array}{l}2 \mathrm{~cm} \text { below the zygomatic } \\
\text { arch in the axial plane }\end{array}$ & $\begin{array}{l}\text { Male }<438.6(100.2) \mathrm{mm}^{2} \\
\text { Female }<347.8(87.5) \mathrm{mm}^{2}\end{array}$ \\
\hline Kaplan 2017 & Skeletal muscle area index & L3 & $\begin{array}{l}\text { Males }<52.4 \mathrm{~cm}^{2} / \mathrm{m}^{2} \\
\text { Female }<38.5 \mathrm{~cm}^{2} / \mathrm{m}^{2}\end{array}$ \\
\hline Ebbeling 2014 & Psoas: L4Vertebral Index & L4 inferior body & $<50$ percentile of $\mathrm{PLVI}(\leq 0.83)$ \\
\hline Akahoshi 2016 & Skeletal muscle area & L3 caudal end & Measured SMA $<80 \%$ estimated SMA \\
\hline Baggerman 2020 & Skeletal muscle area index & L3 & $\begin{array}{l}\text { Males }<41.6 \mathrm{~cm}^{2} / \mathrm{m}^{2} \\
\text { Females }<\text { and } 32.0 \mathrm{~cm}^{2} / \mathrm{m}^{2}\end{array}$ \\
\hline Hwang 2019 & Skeletal muscle area index & L3 & $\begin{array}{l}\text { Males }<55.4 \mathrm{~cm}^{2} / \mathrm{m}^{2} \\
\text { Females }<38.9 \mathrm{~cm}^{2} / \mathrm{m}^{2}\end{array}$ \\
\hline Joyce 2020 & Skeletal muscle area & L3 & $\begin{array}{l}\text { Females }<110 \mathrm{~cm}^{2} \\
\text { Males }<170 \mathrm{~cm}^{2}\end{array}$ \\
\hline
\end{tabular}

about mechanically ventilated critically ill patients found that the prevalence of sarcopenia assessed by SARC-F Questionnaire was 30.2\% [37], which was lower than that in our study. In fact, a systematic review reported that the sensitivity of SARC-F was poor as 0.21 [95\% (CI),0.13-0.31], which leads to underestimate the prevalence of sarcopenia [38]. Other study showed that prevalence of sarcopenia among hospitalized patients who need mechanical ventilation was as high as $60 \%$ [39]. Long-time bedrest and immobilization accelerated skeletal muscle mass loss. Therefore, it is not surprising to observe that the higher prevalence of sarcopenia among critically ill is still needed to be stressed by clinicians.

There were five included studies reported that critically ill patients with sarcopenia did not have a significantly increased risk of mortality than those without sarcopenia. The main reason was that all of these abovementioned studies did not have enough sample size with wide $95 \%$ CI for effect size. After using meta-analysis by fixed model, sarcopenia was significantly associated with a higher risk of mortality. The main reasons accounting for patient admission to ICU are sepsis or cancer-related infection or trauma [40-42]. Our subgroup results found that when considering the reasons for admission, critically ill patients with sarcopenia have an increased risk of mortality, profoundly confirming that sarcopenia could be a prognostic factor in critical illness. Our findings are in line with previous research, which has found that older adults with sarcopenia are at increased risk of mortality in other settings, such as the community [36], nursing homes [43], or in an oncology setting [44-46]. According to published studies, the main reason explaining the relationship between sarcopenia and mortality is lower muscle mass, which has been confirmed as a strong predictor for an increased risk of death [31, 47]. Apart from these factors, critically ill patients often experience complications from worsening conditions, such as severe inflammation, malnutrition, and multiple organ failure, which make patients ill in a vicious circle through the interaction of sarcopenia [48]. Furthermore, being critically ill with sarcopenia may aggravate the possibility of adverse effects resulting from intensive care treatments, including polypharmacy, bed rest, sedation, instrumentation, and mechanical ventilation. All of these multiple factors will increase the risk of mortality in critically ill patients with sarcopenia.

There are several definitions for sarcopenia in these included studies, based on CT scan and the cut-off for low skeletal muscle mass [16]. Therefore, we performed a subgroup analysis based on methods to measure skeletal muscle mass. By using different measurements, including SMI, SMA, MCSA, and TPA, our subgroup analysis found that critically ill patients with sarcopenia are at increased risk of mortality, compared with non- 


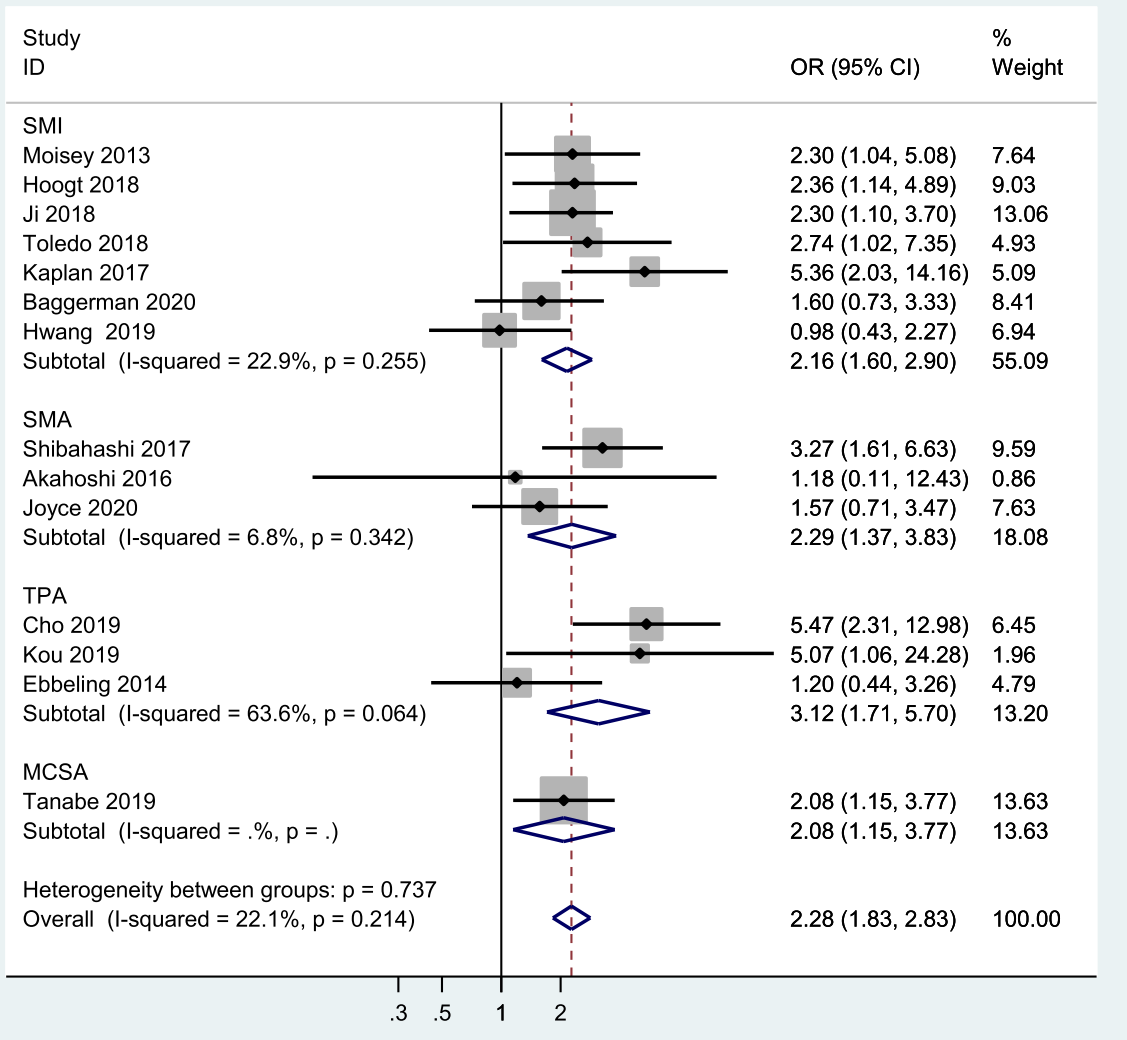

Fig. 5 Subgroup meta-analysis of the association between sarcopenia and mortality in critically ill patients by different definition

sarcopenic critically ill patients. There is no consensus on cut-off for CT scans in defining sarcopenia, leading to differing rates of sarcopenia prevalence and problems in standard clinical practice [49]. According to the latest European Working Group on Sarcopenia in Older People (EWGSOP) update, defining sarcopenia should include an assessment of strength, muscle mass, and detecting sarcopenia severity based on physical performance [50]. However, it is difficult for medical staff to detect strength and physical performance in a critical care setting. The definition of sarcopenia based on a CT scan of muscle mass is currently routine application for critically ill patients, particularly trauma patients, but further studies are required to testify to a standard criteria definition of sarcopenia that can be applicable in clinical practice.

Body composition in people of different ethnicities can vary, given the variety between populations [51]. It is obvious that ethnic and environmental factors, such as industrialization, may lead to varying lifestyles and levels of physical activity, which can affect body composition. Using the same cut-off values for different ethnicities can be problematic. Several academic organizations, such as EWGSOP and The Asian Working Group for
Sarcopenia (AWGS) [52] have formulated different sarcopenia criteria. These two criteria have widely been used in both Asian and Western countries, but with different cut-off values for low skeletal muscle mass. This meta-analysis included many studies from different counties. Our subgroup analysis shows that people who are critically ill with sarcopenia are at increased risk of mortality in both Asian and Western populations, indicating that sarcopenia's impact on critically ill patients is not affected by ethnicity.

Obesity was another important and common condition among critically ill patients, with a prevalence rate of $20 \%$ among ICU patients [53]. The "obesity paradox" is a well-known phenomenon in most chronic wasting diseases. A recent study confirmed the "obesity paradox" (proven in e.g. chronic heart failure or dialysis patients) among hospitalized and ICU patients, indicating a Jshaped association between BMI and mortality. This indicates that moderate obesity was a protective factor for critically ill patients, compared to normal or more severe obesity [54]. However, this study did not adjust muscle mass. Critically ill patients with sarcopenia can coexist with obesity, which is called sarcopenic obesity [55]. A previous review revealed that adults with sarcopenic 


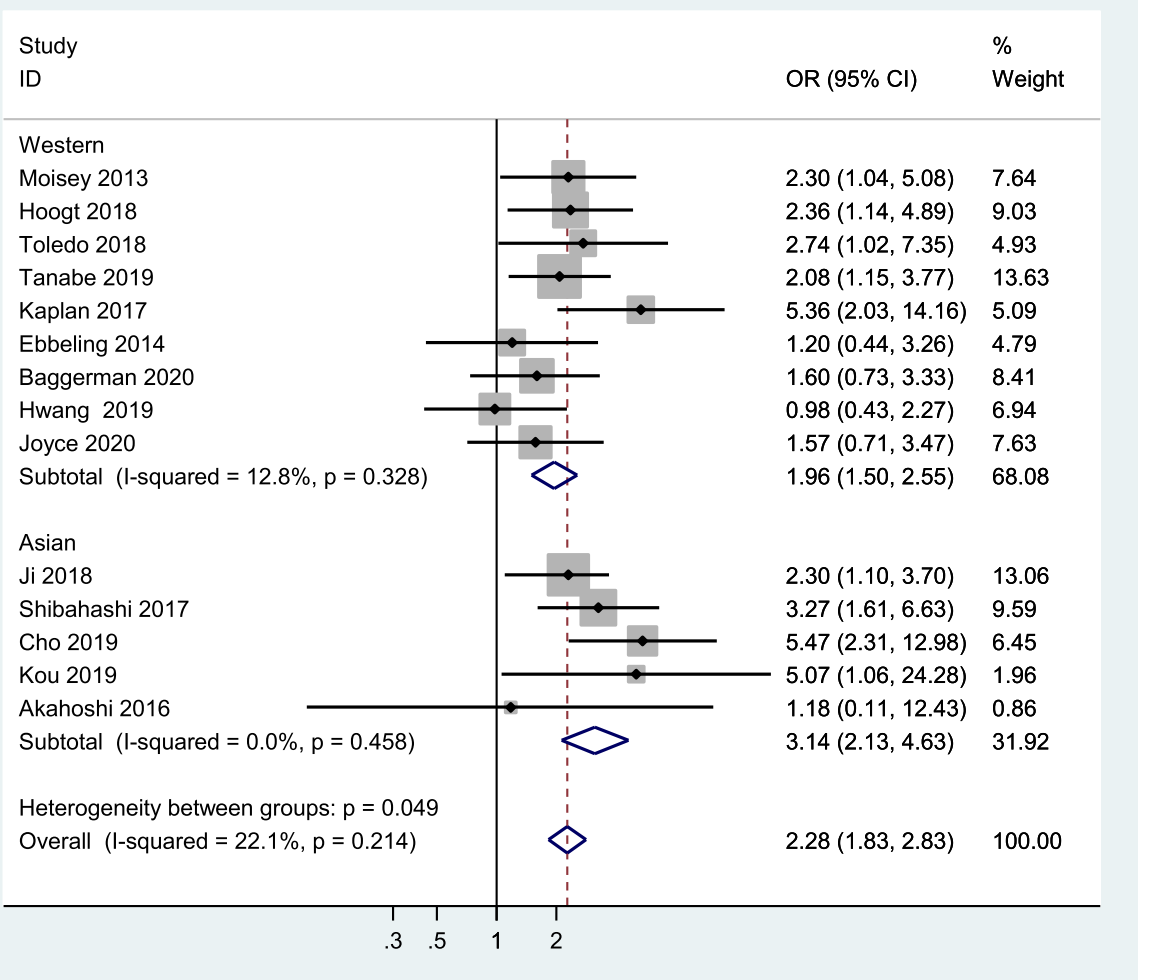

Fig. 6 Subgroup meta-analysis of the association between sarcopenia and mortality in critically ill patients according to region

obesity could be at increased risk for all-cause mortality in different settings [56]. Critically ill patients with sarcopenic obesity have been reported to amplify the risk of mortality [57]. The main reason might be that obese individuals have some characteristics of muscle including fiber-type modifications, mitochondrial dysfunction, lower capillary density, which were linked to impaired functionality [58]. Thus, these changes in body composition combined with sarcopenia could aggravate the risk of morality.

\section{Implications for clinicians, policy, and research}

A crucial aspect of our study is to confirm whether ICU care processes could be amended to improve clinical outcomes in patients with sarcopenia. Recent studies have determined processes that may exert an important impact on sarcopenic patients, include resistance training programmes [59], nutritional support, and intensity of rehabilitation [60]. While research is being conducted on how to reduce patient mortality rates in intensive care units, realising sarcopenia as a risk factor in mortality is also significant, and may help in more effective care planning. To date, many conventional scoring systems, including Acute Physiology and Chronic Health Evaluation (APACHE), sequential organ failure assessment (SOFA), and systemic inflammatory response syndrome (SIRS) have been used to assess critically ill patients $[6,61]$. However, published studies have shown their performance in predicting mortality is modest and cannot satisfy intensive care physicians [62]. Our study supports the value of sarcopenia screening upon ICU admission. Whether measuring muscle mass using CT can improve mortality prediction by adding to conventional scoring systems is worthy of study, given the convenience and simplicity of CT scans.

Our study has a number of strengths. First, to the best of our knowledge, this is the first meta-analysis to quantify the relationship between sarcopenia and mortality in critically ill patients using comprehensive methods and low heterogeneity. Second, we assessed our study using GRADE and recommend using the level of evidence to help medical staff guide clinical work. Our study may also have some limitations. First, the studies that were included in our meta-analysis were all observational studies. They might contain biases, such as selection and confirmation, and cannot determine causation. Second, five studies reported that sarcopenia detection occurred within several days after ICU department admission, meaning that sarcopenia could be a consequence of disease severity. Therefore, this meta-analysis could intensify sarcopenia's impact on mortality. Third, there are several different measurements of muscle mass with various SMI 
cut-offs to determine sarcopenia, resulting in a differing prevalence of sarcopenia and which could eventually lead to different results. Various cut-off of SMI, without a universally agreed consensus on cut-off values for low skeletal muscle, can generate a problem that influences the treatment of patients for sarcopenia. According to the study of Yoowannakul, cut-off values for low skeletal muscle should be adjusted according to gender, normative ethnicity, and age values [63]. When we conducted a subgroup analysis based on muscle measurement, we found the results were similar across various sarcopenia measures. However, unanswered questions remain as to which is the most appropriate measure in an ICU setting. Fourth, most studies performed multivariate analysis to investigate the relationship between sarcopenia and mortality in critically ill patients, yet not all studies adjusted the same confounders, which may have resulted in an underestimation or overestimation of our results. In addition, a number of important confounding factors, such as chronic obstructive pulmonary disease (COPD), obesity, and cardiac failure, which would have influenced sarcopenia's impact on mortality, were not reported in the original studies. Therefore, we could not conduct a subgroup analysis based on these parameters. Fifth, the studies that were included were from different countries, with different hospital systems and a variety of medical technologies and healthcare settings, which could have influenced the outcomes. Sixth, there are different types of outcomes, including inhospital mortality, 30-day mortality, and 1-year mortality, which might have exerted an adverse impact on aggregation. Seventh, two studies used the effect measure with HR not OR; when we pooled the total effect size, we considered HR as OR; therefore, it might overestimate or underestimate the results.

\section{Conclusions}

Our study found that critically ill patients with sarcopenia have an increased 2.28-fold(95\%CI:1.83-2.83) risk of mortality compared to those without sarcopenia. Timely routine assessment for sarcopenia upon ICU admission may provide an important prognostic factor in patient survival. Offering corresponding interventions may help medical staff achieve good patient outcomes. Furthermore, this study also suggests the importance of initiating effective intervention programmes, such as resistance training and appropriate nutritional treatment, which may reduce the risk of mortality.

\section{Abbreviations}

CT: Computed tomography; Mesh: Medical subject headings; NOS: Newcastle Ottawa Scale; OR: Odds ratio; HR: Hazard ratio; SMI: Skeletal muscle index; SMA: Skeletal muscle area; TPA: Total psoas muscle area; MCSA: Masseter cross-sectional area

\section{Supplementary Information}

The online version contains supplementary material available at https://doi. org/10.1186/s12877-021-02276-w.

Additional file 1: Table S1: PRISMA checklist

Additional file 2. Search Strategy

Additional file 3: Table S2: Results of all the studies by using Multivariate Logistic Regression for adjusting covariates. Table S3: Result of the Newcastle-Ottawa scale quality assessment. Table S4: Overall evidence quality. Figure S1: The flow diagram of studies selection. Figure S2: The results of trial sequential analysis on mortality. Figure S3: Subgroup meta-analysis of the association between sarcopenia and mortality in critically ill patients between different age. Figure S4: Begg's and Egger's test for publication bias. Figure S5: Sensitivity analysis of all studies.

\section{Acknowledgements}

The authors thank the staff of the Department of Nursing at Peking Union Medical College Hospital (Dongdan campus) and the School of Nursing at Sun Yat-sen University for their guidance and support.

\section{Authors' contributions}

$\mathrm{XMZ}$ and $\mathrm{DHC}$ were responsible for producing the initial draft of the manuscript. XMZ and DHC were responsible for implementing the search strategy. ASKC and XHX were responsible for the data extraction. YCZ and $\mathrm{DHC}$ were responsible for screening the papers and the quality assessment. XMZ and ASKC responsible for the statistical analysis. ZJE, XHX and ASKC were responsible for the manuscript revision. All authors approved the final version of the manuscript.

\section{Funding}

This research received NO grant from any organization. No sponsors had any role in the design, methods, subject recruitment, data collection, analysis, or preparation of this manuscript.

\section{Availability of data and materials}

All the data can obtain from the PubMed database(https://pubmed.ncbi.n/m. nih.gov).

\section{Declarations}

Ethics approval and consent to participate

Not applicable.

Consent for publication

Not applicable.

\section{Competing interests}

None of the authors has any conflict of interest to declare.

\section{Author details}

${ }^{1}$ Department of Nursing, Chinese Academy of Medical Sciences - Peking Union Medical College, Peking Union Medical College Hospital (Dongdan campus), 100730 Beijing, China. ${ }^{2}$ The Third Affiliated Hospital of Guangdong Medical University (LongJiang hospital of Shunde District, Foshan,

Guangdong, China. ${ }^{3}$ Department of Nursing, The Second People's Hospital of Shenzhen, The First Affiliated Hospital of Shenzhen University, Shenzhen,

China. ${ }^{4}$ School of Nursing, Sun Yat-sen University, Guangzhou, China.

${ }^{5}$ Department of Nursing, The Third Affiliated Hospital of Guangzhou Medical University, Guangzhou, China. 'Department of Rehabilitation Sciences, The Hong Kong Polytechnic University, Hong Kong, China.

Received: 30 October 2020 Accepted: 10 May 2021

Published online: 02 June 2021

References

1. Darmon M, Bourmaud A, Georges Q, Soares M, Jeon K, Oeyen S, Rhee CK, Gruber $\mathrm{P}$, Ostermann M, Hill QA, et al. Changes in critically ill cancer patients' short-term outcome over the last decades: results of systematic 
review with meta-analysis on individual data. Intensive care medicine. 2019; 45(7):977-87.

2. Ceniccola GD, Holanda TP, Pequeno RSF, Mendonca VS, Oliveira ABM, Carvalho LSF, de Brito-Ashurst I, Araujo WMC. Relevance of AND-ASPEN criteria of malnutrition to predict hospital mortality in critically ill patients: A prospective study. J Crit Care. 2018;44:398-403.

3. Rudd KE, Johnson SC, Agesa KM, Shackelford KA, Tsoi D, Kievlan DR, Colombara DV, Ikuta KS, Kissoon N, Finfer S, et al. Global, regional, and national sepsis incidence and mortality, 1990-2017: analysis for the Global Burden of Disease Study. Lancet. 2020;395(10219):200-11.

4. Mayr VD, Dunser MW, Greil V, Jochberger S, Luckner G, Ulmer H, Friesenecker BE, Takala J, Hasibeder WR. Causes of death and determinants of outcome in critically ill patients. Crit Care (London England). 2006;10(6): R154.

5. Lee CW, Kou HW, Chou HS, Chou HH, Huang SF, Chang CH, Wu CH, Yu MC, Tsai HI. A combination of SOFA score and biomarkers gives a better prediction of septic AKI and in-hospital mortality in critically ill surgical patients: a pilot study. World journal of emergency surgery: WJES. 2018;13:41.

6. Kaukonen KM, Bailey M, Pilcher D, Cooper DJ, Bellomo R. The systemic inflammatory response syndrome criteria and their differential association with mortality. J Crit Care. 2018;46:29-36.

7. Lee H, Lim CW, Hong HP, Ju JW, Jeon YT, Hwang JW, Park HP. Efficacy of the APACHE II score at ICU discharge in predicting post-ICU mortality and ICU readmission in critically ill surgical patients. Anaesthesia intensive care. 2015;43(2):175-86

8. Cruz-Jentoft AJ, Baeyens JP, Bauer JM, Boirie Y, Cederholm T, Landi F, Martin FC, Michel JP, Rolland Y, Schneider SM, et al. Sarcopenia: European consensus on definition and diagnosis: Report of the European Working Group on Sarcopenia in Older People. Age Ageing. 2010;39(4):412-23.

9. Kizilarslanoglu MC, Kuyumcu ME, Yesil Y, Halil M. Sarcopenia in critically ill patients. Journal of anesthesia. 2016;30(5):884-90.

10. Moisey LL, Mourtzakis M, Cotton BA, Premji T, Heyland DK, Wade CE, Bulger E, Kozar RA. Skeletal muscle predicts ventilator-free days, ICU-free days, and mortality in elderly ICU patients. Crit Care. 2013;17(5):R206.

11. Baggerman MR, van Dijk DPJ, Winkens B, van Gassel RJJ, Bol ME, Schnabel RM, Bakers FC, Olde Damink SWM, van de Poll MCG. Muscle wasting associated co-morbidities, rather than sarcopenia are risk factors for hospital mortality in critical illness. J Crit Care. 2019;56:31-6.

12. Yeung SSY, Reijnierse EM, Pham VK, Trappenburg MC, Lim WK, Meskers CGM, Maier AB: Sarcopenia and its association with falls and fractures in older adults: A systematic review and meta-analysis. Journal of cachexia, sarcopenia and muscle 2019, 10(3):485-500.

13. Zhang X, Huang P, Dou Q, Wang C, Zhang W, Yang Y, Wang J, Xie X, Zhou J, Zeng Y: Falls among older adults with sarcopenia dwelling in nursing home or community: A meta-analysis. Clinical nutrition (Edinburgh, Scotland) 2020, 39(1):33-39.

14. Chang KV, Hsu TH, Wu WT, Huang KC, Han DS: Association Between Sarcopenia and Cognitive Impairment: A Systematic Review and MetaAnalysis. Journal of the American Medical Directors Association 2016, 17(12): 1164.e1167-1164.e1115.

15. Ando $Y$, Ishigami M, Ito T, Ishizu $Y$, Kuzuya $T$, Honda T, Ishikawa T, Fujishiro M. Sarcopenia impairs health-related quality of life in cirrhotic patients. Eur J Gastroenterol Hepatol. 2019;31(12):1550-6.

16. Xia W, Barazanchi AWH, MacFater WS, Hill AG. The impact of computed tomography-assessed sarcopenia on outcomes for trauma patients - a systematic review and meta-analysis. Injury. 2019;50(9):1565-76.

17. Shibahashi K, Sugiyama K, Kashiura M, Hamabe Y. Decreasing skeletal muscle as a risk factor for mortality in elderly patients with sepsis: a retrospective cohort study. Journal of intensive care. 2017;5:8.

18. de Hoogt PA, Reisinger KW, Tegels JJW, Bosmans J, Tijssen F, Stoot J. Functional Compromise Cohort Study (FCCS): Sarcopenia is a Strong Predictor of Mortality in the Intensive Care Unit. World J Surg. 2018;42(6): $1733-41$.

19. Toledo DO, Carvalho AM, Oliveira A, Toloi JM, Silva AC, Francisco de Mattos Farah J, Prado CM, Silva JM, Jr. The use of computed tomography images as a prognostic marker in critically ill cancer patients. Clin Nutr ESPEN. 2018;25: $114-20$.

20. Cho WH, Choi YY, Byun KS, Lee SE, Jeon D, Kim YS, Han J, Yeo HJ: Prognostic Value of Sarcopenia for Long-Term Mortality in Extracorporeal Membrane Oxygenation for Acute Respiratory Failure. ASAIO journal (American Society for Artificial Internal Organs: 1992) 2019.
21. Kou HW, Yeh CH, Tsai HI, Hsu CC, Hsieh YC, Chen WT, Cheng HT, Yu MC, Lee CW. Sarcopenia is an effective predictor of difficult-to-wean and mortality among critically ill surgical patients. PLoS One. 2019;14(8): e0220699.

22. Hwang F, McGreevy CM, Pentakota SR, Verde D, Park JH, Berlin A, Glass NE, Livingston DH, Mosenthal A. Sarcopenia is Predictive of Functional Outcomes in Older Trauma Patients. Cureus. 2019;11(11):e6154.

23. Joyce PR, O'Dempsey R, Kirby G, Anstey C. A retrospective observational study of sarcopenia and outcomes in critically ill patients. Anaesthesia intensive care. 2020;48(3):229-35.

24. Akahoshi T, Yasuda M, Momii K, Kubota K, Shono Y, Kaku N, Tokuda K, Nagata T, Yoshizumi T, Shirabe $K$, et al. Sarcopenia is a predictive factor for prolonged intensive care unit stays in high-energy blunt trauma patients. Acute medicine surgery. 2016;3(4):326-31.

25. Ebbeling L, Grabo DJ, Shashaty M, Dua R, Sonnad SS, Sims CA, Pascual JL, Schwab CW, Holena DN. Psoas:lumbar vertebra index: central sarcopenia independently predicts morbidity in elderly trauma patients. European journal of trauma emergency surgery: official publication of the European Trauma Society. 2014;40(1):57-65

26. Liberati A, Altman DG, Tetzlaff J, Mulrow C, Gøtzsche PC, loannidis JP, Clarke M, Devereaux PJ, Kleijnen J, Moher D. The PRISMA statement for reporting systematic reviews and meta-analyses of studies that evaluate healthcare interventions: explanation and elaboration. BMJ. 2009;339:b2700.

27. Stang A. Critical evaluation of the Newcastle-Ottawa scale for the assessment of the quality of nonrandomized studies in meta-analyses. Eur J Epidemiol. 2010;25(9):603-5.

28. Cardinale F, Ciprandi G, Barberi S, Bernardini R, Caffarelli C, Calvani M, Cavagni G, Galli E, Minasi D, Del Giudice MM, et al: Consensus statement of the Italian society of pediatric allergy and immunology for the pragmatic management of children and adolescents with allergic or immunological diseases during the COVID-19 pandemic. Italian Journal of Pediatrics 2020, 46(1).

29. Ju S, Choi SM, Park YS, Lee CH, Lee SM, Yoo CG, Kim YW, Han SK, Lee J. Rapid Muscle Loss Negatively Impacts Survival in Critically III Patients With Cirrhosis. J Intensive Care Med. 2020;35(7):663-71.

30. Kim YJ, Seo DW, Kang J, Huh JW, Kim KW, Kim WY. Impact of Body Composition Status on 90-Day Mortality in Cancer Patients with Septic Shock: Sex Differences in the Skeletal Muscle Index. J Clin Med 2019, 8(10).

31. Weijs PJ, Looijaard WG, Dekker IM, Stapel SN, Girbes AR, Oudemans-van Straaten HM, Beishuizen A. Low skeletal muscle area is a risk factor for mortality in mechanically ventilated critically ill patients. Crit Care (London England). 2014;18(2):R12.

32. Toptas M, Yalcin M, Akkoc I, Demir E, Metin C, Savas Y, Kalyoncuoglu M, Can MM. The Relation between Sarcopenia and Mortality in Patients at Intensive Care Unit. Biomed Res Int. 2018;2018:5263208.

33. Tanabe C, Reed MJ, Pham TN, Penn K, Bentov I, Kaplan SJ. Association of Brain Atrophy and Masseter Sarcopenia With 1-Year Mortality in Older Trauma Patients. JAMA surgery 2019.

34. Kaplan SJ, Pham TN, Arbabi S, Gross JA, Damodarasamy M, Bentov I, Taitsman LA, Mitchell SH, Reed MJ. Association of Radiologic Indicators of Frailty With 1-Year Mortality in Older Trauma Patients: Opportunistic Screening for Sarcopenia and Osteopenia. JAMA Surg. 2017;152(2):e164604.

35. Ji Y, Cheng B, Xu Z, Ye H, Lu W, Luo X, Fu S, Fang X. Impact of sarcopenic obesity on 30-day mortality in critically ill patients with intra-abdominal sepsis. J Crit Care. 2018:46:50-4

36. Liu P, Hao Q, Hai S, Wang H, Cao L, Dong B. Sarcopenia as a predictor of allcause mortality among community-dwelling older people: A systematic review and meta-analysis. Maturitas. 2017;103:16-22.

37. Lee ZY, Ong SP, Ng CC, Yap CSL, Engkasan JP, Barakatun-Nisak MY, Heyland DK, Hasan MS: Association between ultrasound quadriceps muscle status with premorbid functional status and 60-day mortality in mechanically ventilated critically ill patient: A single-center prospective observational study. Clinical nutrition (Edinburgh, Scotland) 2020.

38. Ida S, Kaneko R, Murata K. SARC-F for Screening of Sarcopenia Among Older Adults: A Meta-analysis of Screening Test Accuracy. J Am Med Dir Assoc 2018;19(8):685-9.

39. Lopez-Ruiz A, Kashani K. Assessment of muscle mass in critically ill patients: role of the sarcopenia index and images studies. Curr Opin Clin Nutr Metab Care. 2020;23(5):302-11.

40. Sakr Y, Jaschinski U, Wittebole X, Szakmany T, Lipman J, Namendys-Silva SA, Martin-Loeches I, Leone M, Lupu MN, Vincent لL. Sepsis in Intensive Care 
Unit Patients: Worldwide Data From the Intensive Care over Nations Audit. Open forum infectious diseases. 2018;5(12):ofy313.

41. Taccone FS, Artigas AA, Sprung CL, Moreno R, Sakr Y, Vincent JL. Characteristics and outcomes of cancer patients in European ICUs. Crit Care (London England). 2009;13(1):R15.

42. Magee F, Wilson A, Bailey MJ, Pilcher D, Secombe PJ, Young P, Bellomo R. Trauma-related admissions to intensive care units in Australia: the influence of Indigenous status on outcomes. The Medical journal of Australia. 2019; 210(11):493-8

43. Zhang X, Wang C, Dou Q, Zhang W, Yang Y, Xie X: Sarcopenia as a predictor of all-cause mortality among older nursing home residents: a systematic review and meta-analysis. BMJ open 2018, 8(11):e021252

44. Buentzel J, Heinz J, Bleckmann A, Bauer C, Rover C, Bohnenberger H, Saha S, Hinterthaner M, Baraki H, Kutschka I, et al: Sarcopenia as Prognostic Factor in Lung Cancer Patients: A Systematic Review and Meta-analysis. Anticancer research 2019, 39(9):4603-4612.

45. Su H, Ruan J, Chen T, Lin E, Shi L. CT-assessed sarcopenia is a predictive factor for both long-term and short-term outcomes in gastrointestinal oncology patients: a systematic review and meta-analysis. Cancer imaging: the official publication of the International Cancer Imaging Society. 2019; 19(1):82.

46. Ubachs J, Ziemons J, Minis-Rutten IJG, Kruitwagen R, Kleijnen J, Lambrechts S, Olde Damink SWM, Rensen SS, Van Gorp T: Sarcopenia and ovarian cancer survival: a systematic review and meta-analysis. Journal of cachexia, sarcopenia and muscle 2019, 10(6):1165-1174.

47. Abramowitz MK, Hall CB, Amodu A, Sharma D, Androga L, Hawkins M. Muscle mass, BMI, and mortality among adults in the United States: A population-based cohort study. PloS one. 2018;13(4):e0194697.

48. Gropper S, Hunt D, Chapa DW. Sarcopenia and Psychosocial Variables in Patients in Intensive Care Units: The Role of Nutrition and Rehabilitation in Prevention and Treatment. Crit Care Nurs Clin N Am. 2019;31(4):489-99.

49. Lee K, Shin Y, Huh J, Sung YS, Lee IS, Yoon KH, Kim KW. Recent Issues on Body Composition Imaging for Sarcopenia Evaluation. Korean J Radiol. 2019; 20(2):205-17.

50. Cruz-Jentoft AJ, Bahat G, Bauer J, Boirie Y, Bruyère O, Cederholm T, Cooper C, Landi F, Rolland Y, Sayer AA, et al. Sarcopenia: revised European consensus on definition and diagnosis. Age Ageing. 2019;48(4):601.

51. Wulan SN, Westerterp KR, Plasqui G. Ethnic differences in body composition and the associated metabolic profile: a comparative study between Asians and Caucasians. Maturitas. 2010;65(4):315-9.

52. Chen LK, Woo J, Assantachai P, Auyeung TW, Chou MY, lijima K, Jang HC, Kang L, Kim M, Kim S, et al. Asian Working Group for Sarcopenia: 2019 Consensus Update on Sarcopenia Diagnosis and Treatment. J Am Med Dir Assoc. 2020:21(3):300-7.e302.

53. Sakr Y, Alhussami I, Nanchal R, Wunderink RG, Pellis T, Wittebole X, MartinLoeches I, François B, Leone M, Vincent JL. Being Overweight Is Associated With Greater Survival in ICU Patients: Results From the Intensive Care Over Nations Audit. Critical care medicine. 2015;43(12):2623-32.

54. Schetz $M$, De Jong A, Deane AM, Druml W, Hemelaar P, Pelosi P, Pickkers $P$, Reintam-Blaser A, Roberts J, Sakr Y, et al. Obesity in the critically ill: a narrative review. Intensive care medicine. 2019:45(6):757-69.

55. Tieland M, van Dronkelaar C, Boirie Y. Sarcopenic obesity in the ICU. Curr Opin Clin Nutr Metab Care. 2019;22(2):162-6.

56. Zhang X, Xie X, Dou Q, Liu C, Zhang W, Yang Y, Deng R, Cheng ASK: Association of sarcopenic obesity with the risk of all-cause mortality among adults over a broad range of different settings: a updated meta-analysis. BMC geriatrics 2019, 19(1):183.

57. Feigin VL, Nguyen G, Cercy K, Johnson CO, Alam T, Parmar PG, Abajobir AA, Abate KH, Abd-Allah F, Abejie AN, et al: Global, Regional, and CountrySpecific Lifetime Risks of Stroke, 1990 and 2016. The New England journal of medicine 2018, 379(25):2429-2437.

58. Ryan A, Wallace E, O'Hara P, Smith SM. Multimorbidity and functional decline in community-dwelling adults: a systematic review. Health Qual Life Outcomes. 2015;13:168-8.

59. Adams SC, Segal RJ, McKenzie DC, Vallerand JR, Morielli AR, Mackey JR, Gelmon K, Friedenreich CM, Reid RD, Courneya KS. Impact of resistance and aerobic exercise on sarcopenia and dynapenia in breast cancer patients receiving adjuvant chemotherapy: a multicenter randomized controlled trial. Breast cancer research treatment. 2016;158(3):497-507.

60. Beckwee D, Delaere A, Aelbrecht S, Baert V, Beaudart C, Bruyere O, de SaintHubert M, Bautmans I. Exercise Interventions for the Prevention and
Treatment of Sarcopenia. A Systematic Umbrella Review. J Nutr Health Aging. 2019;23(6):494-502.

61. Ho KM. Combining sequential organ failure assessment (SOFA) score with acute physiology and chronic health evaluation (APACHE) II score to predict hospital mortality of critically ill patients. Anaesthesia intensive care. 2007; 35(4):515-21.

62. Zhang XM, Zhang WW, Yu XZ, Dou QL, Cheng AS. Comparing the performance of SOFA, TPA combined with SOFA and APACHE-II for predicting ICU mortality in critically ill surgical patients: A secondary analysis. Clin Nutr. 2020;39(9):2902-9.

63. Yoowannakul S, Tangvoraphonkchai K, Davenport A. The prevalence of muscle wasting (sarcopenia) in peritoneal dialysis patients varies with ethnicity due to differences in muscle mass measured by bioimpedance. Eur J Clin Nutr. 2018;72(3):381-7.

\section{Publisher's Note}

Springer Nature remains neutral with regard to jurisdictional claims in published maps and institutional affiliations.
Ready to submit your research? Choose BMC and benefit from:

- fast, convenient online submission

- thorough peer review by experienced researchers in your field

- rapid publication on acceptance

- support for research data, including large and complex data types

- gold Open Access which fosters wider collaboration and increased citations

- maximum visibility for your research: over $100 \mathrm{M}$ website views per year

At $\mathrm{BMC}$, research is always in progress.

Learn more biomedcentral.com/submissions 